\title{
NLRX1 is not involved in the host defense against Escherichia
}

\section{coli induced pyelonephritis [version 1; peer review: 1}

\section{approved, 1 approved with reservations]}

\author{
Lotte Kors ${ }^{1}$, Loes M. Butter ${ }^{1}$, Nike Claessen ${ }^{1}$, Gwendoline J.D. Teske ${ }^{1}$, \\ Stephen E. Girardin'2, Sandrine Florquin'1, Jaklien C. Leemans ${ }^{1}$ \\ 1Department of Pathology, Academic Medical Center, Amsterdam, The Netherlands \\ ${ }^{2}$ Department of Laboratory Medicine and Pathobiology, University of Toronto, Toronto, Canada
}

V1 First published: 06 Aug 2018, 7:1197
https://doi.org/10.12688/f1000research.15361.1

Second version: 11 Apr 2019, 7:1197

https://doi.org/10.12688/f1000research.15361.2

Latest published: 24 Sep 2019, 7:1197

https://doi.org/10.12688/f1000research.15361.3

\section{Abstract}

Background: Urinary tract infections (UTIs) caused by uropathogenic Escherichia coli (E. coli) are one of the most prominent infections that have serious impact on kidney functioning and the development of chronic kidney disease. NOD-like receptor (NLR)X1 is an innate immune receptor that is important for immune metabolism and regulation, with as yet an unknown role in UTI and the pathophysiology of pyelonephritis.

Methods: Wild-type (WT) and NLRX1 Knock-out (KO) female mice were subjected to UTI by intravesically inoculation of uropathogenic $E$. coli and sacrificed at $24 \mathrm{~h}$ and $48 \mathrm{~h}$ after infection after which bacterial burden and the inflammatory response in the bladder and kidney were studied. Ex vivo we studied the role of NLRX1 during the LPS induced pro-inflammatory cytokine response and phagocytosis of $E$. coli by granulocytes and monocytes.

Results: Here, we report that during early experimental UTI NLRX1 absence reduces bacterial clearance in the bladder and dampens the inflammatory cytokine response, whereas in the kidney NLRX1 does not affect bacterial burden or cytokine response. In addition, we found that NLRX1 is not essential for the pro-inflammatory cytokine secretion by granulocytes and monocytes in response to LPS nor for bacterial phagocytosis.

Conclusion: Together, we report that NLRX1 is important in enhancing the early host defense against uropathogenic $E$. coli in the bladder but does not affect the development of pyelonephritis.

\section{Keywords}

Innate Immune Receptor NLRX1, Lower and Upper UTI, Pyelonephritis, Animal model, Escherichia coli

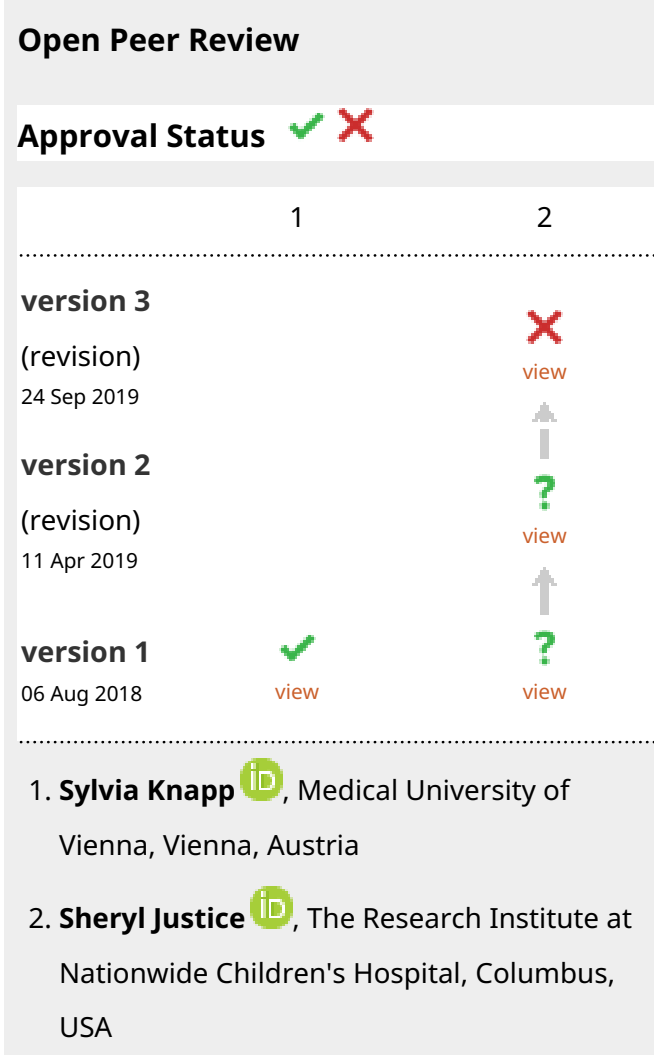

Any reports and responses or comments on the article can be found at the end of the article. 


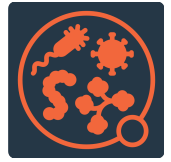

This article is included in the Pathogens

gateway.

Corresponding author: Lotte Kors (I.kors@amc.uva.nl)

Author roles: Kors L: Conceptualization, Formal Analysis, Investigation, Project Administration, Validation, Visualization, Writing Original Draft Preparation; Butter LM: Investigation; Claessen N: Investigation; Teske GJD: Investigation; Girardin SE: Resources; Florquin S: Conceptualization, Writing - Review \& Editing; Leemans JC: Conceptualization, Funding Acquisition, Supervision, Writing Review \& Editing

Competing interests: No competing interests were disclosed.

Grant information: This study was supported by The Netherlands Organization for Scientific Research NWO grant [91712386] to JCL. The funders had no role in study design, data collection and analysis, decision to publish, or preparation of the manuscript.

Copyright: $\odot 2018$ Kors $L$ et al. This is an open access article distributed under the terms of the Creative Commons Attribution License, which permits unrestricted use, distribution, and reproduction in any medium, provided the original work is properly cited. Data associated with the article are available under the terms of the Creative Commons Zero "No rights reserved" data waiver (CCO 1.0 Public domain dedication).

How to cite this article: Kors L, Butter LM, Claessen N et al. NLRX1 is not involved in the host defense against Escherichia coli induced pyelonephritis [version 1; peer review: 1 approved, 1 approved with reservations] F1000Research 2018, 7:1197 https://doi.org/10.12688/f1000research.15361.1

First published: 06 Aug 2018, 7:1197 https://doi.org/10.12688/f1000research.15361.1 


\section{Introduction}

Toll like receptors (TLRs) and NOD-like receptors (NLRs) are members of a large family of extracellular and intracellular pattern recognition receptors (PRRs) that trigger immune responses to prevent pathogen invasion and growth ${ }^{1,2}$. Urinary tract infections (UTIs) are common bacterial infections in humans, that occur most commonly in women and children ${ }^{3}$. UTIs are caused by the presence of uropathogenic bacteria, usually Escherichia coli (E. coli), in the lower urinary tract (bladder) that overcome the host innate immune defense. When the infection ascends from the bladder via the ureters to the upper renal pyelum, lower UTI can lead to acute pyelonephritis. If untreated pyelonephritis can have serious implications for renal functioning and the development of damage and scarring ${ }^{4,5}$. Antimicrobial resistance among UTIs are increasing ${ }^{6,7}$, therefore new insights in host defense mechanisms are required to obtain new targets for therapy.

TLRs are known to play an important role in the host response to UTIs ${ }^{8}$, whereas the role of NLRs herein is unclear. NODlike receptor X1 (NLRX1) is an ubiquitously expressed PRR in mitochondria that controls mitochondrial activity in tubular epithelial cells and hepatocytes, and in this way effects respectively ischemic acute kidney disease and liver steatosis ${ }^{9,10}$. Other functions for NLRX1 include negative regulation of antiviral immunity $^{11}$, and inhibition of NF- $\mathrm{KB}$ signaling by disrupting interaction of TRAF6 and IKK ${ }^{12,13}$. Given these studies, NLRX1 could play a potential role during the pathophysiology of acute bacterial infections such as pyelonephritis.

To get more insight in NLRX1 functioning during bacterial infection we investigated in the present study the role of NLRX1 during uropathogenic E. coli-induced lower and upper UTI in mice. We found that although NLRX1 absence enhances bacterial burden in the bladder during the early phase of infection, NLRX1 is not involved in the host defense against pyelonephritis.

\section{Methods}

Animals

NLRX1 KO mice with a C57BL6/J background were generated as described previously ${ }^{14}$ and bred at the animal facility of the Academic Medical Center (AMC) in Amsterdam, The Netherlands. Age- and gender-matched C57BL6/J WT mice were obtained from Charles River (Maastricht, The Netherlands). Animals were housed in individual ventilated cages (IVCs) with bedding and cage enrichment that were kept under standard environmental conditions (temperature, humidity, ventilation, light/dark cycle) and under specific pathogen-free conditions (SPF) with ad libitum access to water and food. The mice were allowed to acclimatize for a week before starting the experimental procedures.

\section{Animal experimental procedures}

The in vivo study was performed with 2 experimental groups: 1) WT $(n=8)$ and 2) NLRX1-KO $(n=8)$ and 2 sham/control groups: 3) WT (n=4) 4) NLRX1-KO (n=4). Each experimental group was subjected for two time points ( $24 \mathrm{~h}$ and $48 \mathrm{~h}$ ) to UTI as described previously ${ }^{15}$ and briefly explained later. The total number of mice per in vivo experimental group was 16 and the total number per sham/control group was 4 . To reach a statistical significant effect of NLRX1 deficiency the number of 8 mice per experimental group was based on a variation coefficient of $15 \%$, a minimal relative effect of $30 \%$, a $\mathrm{P}$ value of $5 \%$ and a power of $80 \%$, that were based on previous studies done in our group ${ }^{15-17}$. For both experimental and sham/control groups 11-12 week old female mice (median weights: WT; 19,6 and NLRX1-KO; 21,3 grams) were used. Each experimental group was divided in 2 cages of 3 and 5 animals and in the sham/control group 4 animals per cage were kept. For the experimental group uropathogenic E. coli 1677, isolated from an uroseptic patient, was cultured in the laboratory in sterile Tryptic Soy Broth (TSB) overnight at $37^{\circ} \mathrm{C}, 5 \% \mathrm{CO}_{2}$. The next day, in the morning this suspension was diluted 1:100 in fresh TSB and in 2-3h cultured to optical density OD620 ${ }_{\mathrm{nm}}=1$ was reached (measured with a spectrophotometer (DU640, Beckman, USA)). Subsequently bacteria were spun down for $14 \mathrm{~min}$ at $4000 \mathrm{rpm}$ at $4^{\circ} \mathrm{C}$, washed three times and resuspended in $10 \mathrm{~mL}$ sterile PBS. The same day, in the animal facility, under general anaesthesia $(10 \mu \mathrm{l} / 1 \mathrm{~g}$ body weight of FFM mixture, containing $1.25 \mathrm{mg} / \mathrm{ml}$ midazolam (Dormicum ${ }^{\circledR}$, Roche, Woerden, The Netherlands), $0.08 \mathrm{mg} / \mathrm{ml}$ fentanyl citrate $/ 2.5 \mathrm{mg} / \mathrm{ml}$ fluanisone (Hypnorm, Veta Pharma Ltd., Leeds, UK)) that was given intraperitoneal, mice were via the urethra intravesically inoculated with $8 * 10^{8} \mathrm{CFU}$ in a $100 \mu$ volume. Mice in the sham/control group underwent the same procedure with administration of $100 \mu \mathrm{l}$ sterile PBS. CFU concentrations in the inoculum were determined by plating 10 -fold serial dilutions on blood-agar plates at $37^{\circ} \mathrm{C}, 5 \% \mathrm{CO}_{2}$ overnight. Mice were sacrificed 24 and 48 hour post-inoculation by cardiac puncture under $4 \%$ isoflurane $/ \mathrm{O}_{2}$ followed by cervical dislocation. Blood was collected in lithium-heparin containing tubes and kidneys and bladders were collected for further analysis. In the WT $24 \mathrm{~h}$ group one animal reached, because of signs of severe sepsis, the human end point and was excluded from further data analysis. The animals used to study leukocyte composition and ex vivo granulocyte and monocyte functioning contained 2 experimental groups: 1) WT (n=6) and 2) NLRX1-KO (n=6) and were sacrificed as described earlier for the in vivo experiments. Mice used for the ex vivo experimental groups were 13-14 week old female mice (median weights: WT;26.5 and NLRX1-KO;26.6 grams). The total number of mice per ex vivo experimental group was 6 . In the WT group one sample was excluded from further data analysis due to low blood gain.

\section{Ethics statement}

All animal procedures were ethically approved under DPA 25 AB-1 by the Animal Care and Use Committee of the Academic Medical Center Amsterdam and were conducted in compliance with the ARRIVE guidelines (NC3Rs).

\section{Bacterial outgrowth determination}

Bladder $20 \%(\mathrm{w} / \mathrm{v})$ and left kidney $10 \%$ (w/v) tissues were homogenized in sterile PBS with a tissue homogenizer (Polytron PT1300D homogenizer, Kinematica AG). To determine bacterial loads 10-fold serial dilutions of bladder- and kidneyhomogenates were plated onto blood agar plates. Colonies were counted $16 \mathrm{~h}$ after incubation at $37^{\circ} \mathrm{C}$. 
Leukocyte composition and count

Absolute leukocyte number in blood was measured with a Coulter Counter (Beckmann Coulter Inc., Fullerton, CA). To assess relative leukocyte composition, $100 \mu \mathrm{l}$ whole blood erythrocytes were lysed by adding $2 \mathrm{ml}$ lysis buffer $\left(8.3 \mathrm{~g} / \mathrm{L} \mathrm{NH} \mathrm{NH}_{4} \mathrm{Cl}\right.$, $1.0 \mathrm{~g} / \mathrm{L} \mathrm{KHCO}_{3}, 0.1 \mathrm{mM}$ EDTA, $\mathrm{pH} 7.4$ ) for $15 \mathrm{~min}$ at RT. The remaining cells, leukocytes, were washed once, centrifuged and resuspended in FACS buffer $\left(0.5 \%\right.$ BSA, $0.01 \% \quad \mathrm{NaN}_{3}$, $0.35 \mathrm{mM}$ EDTA in PBS) and were measured by flow cytometry on a FACS Canto (BD Biosciences, San Jose, CA, USA) and analyzed with FlowJo version 10 software. Living cells, lymphocyte, granulocyte and monocyte populations were gated based on forward-scattered light (FSC)/side-scattered light (SCC).

\section{Whole blood stimulation}

Whole blood of WT and NLRX1 KO mice was incubated at $37^{\circ} \mathrm{C}, 5 \% \mathrm{CO}_{2}$ in $10 \mathrm{ng} / \mathrm{mL}$ LPS (cat no. 14391, Sigma-Aldrich, Zwijndrecht, The Netherlands) conditioned RPMI medium (Thermo fisher Scientific, Waltham, MA, USA) containing 10\% FCS (Invitrogen, Carlsbad, CA, USA) with $2 \mathrm{mM}$ L-glutamine and $100 \mathrm{U} / \mathrm{mL}$ penicillin/streptomycin (all from Thermo fisher Scientific, Waltham, MA, USA). After $14 \mathrm{~h}$, cells were spun down (5 min, $4000 \mathrm{rpm}$ ) and supernatants were collected and stored at $-20^{\circ} \mathrm{C}$ prior to use for cytokine measurements.

\section{Phagocytosis assay}

Phagocytosis by granulocytes and monocytes was measured with the PHAGOTEST (cat no. 10-0100, Glycotope Biotechnology, Heidelberg, Germany) according to the manufacturer's instructions. Briefly, $100 \mu \mathrm{l}$ of heparinized whole blood was incubated with opsonized FITC- labeled E. coli for 10 minutes in a $37^{\circ} \mathrm{C}$ water bath, whereas the negative controls remained on ice. After phagocytosis was stopped the surface signal was quenched. After lysing the erythrocytes and fixation of the leukocytes, phagocytic capacity was measured by flow cytometry on a FACS Canto (BD Biosciences, San Jose, CA, USA) and analyzed with FlowJo version 10 software.

\section{Enzyme-linked immunoabsorbance assay (ELISA)}

Bladder $5 \%(\mathrm{w} / \mathrm{v})$ and kidney $10 \%(\mathrm{w} / \mathrm{v})$ tissues from $24 \mathrm{~h}$ and $48 \mathrm{~h}$ UTI subjected WT and NLRX1 KO mice were homogenized with a tissue homogenizer (Polytron PT1300D homogenizer, Kinematica AG) in Greenberger lysis buffer (GLB) (300mM NaCl, 30mM Tris, $2 \mathrm{mM} \mathrm{MgCl}, 2 \mathrm{mM} \mathrm{CaCl} 2,1 \%$ (v/v) Triton $\mathrm{X}-100, \mathrm{pH}$ set at 7.4, supplemented with Protease Inhibi- tor Cocktail II (cat no. p8340, Sigma-Aldrich, Sigma-Aldrich, Zwijndrecht, The Netherlands). Levels of keratinocyte-derived chemokine (KC), macrophage inflammatory protein-2 (MIP-2), monocyte chemoattractant protein 1 (MCP-1), interleukin $1 \beta$ (IL1 $\beta$ ), interleukin 6 (IL6), tumor necrosis factor alpha (TNF $\alpha$ ) and mouse myeloid peroxidase (MPO) were determined in bladder and kidney homogenates and whole blood plasma $(\mathrm{KC}$, TNF $\alpha$ and IL6 only) by duo set ELISAs (cat no. MKC00B, MM200, MJE00, MLB00C, M6000B, MTA00B, DY3667, R\&D Systems, Abingdon, UK), performed according to the supplied protocols. ELISA data measured in bladder and kidney homogenates was adjusted for total protein concentration as determined by BCA protein assay (cat no. B9643, Sigma-Aldrich, Sigma-Aldrich, Zwijndrecht, The Netherlands) developed with $4 \%$ $\mathrm{CuSO}_{4}$.

\section{Plasma biochemical analysis}

From hepanarized blood, plasma was obtained from the upper phase after spinning the tube for 10 minutes at $2000 \mathrm{rpm}$. Urea and creatinine levels in plasma were determined at room temperature by colorimetric enzyme reactions involving creatinase and urease and analyzed on the Cobas c702 Chemistry Analyzer (Roche Diagnostics, Indianapolis, IN, USA) according to standard diagnostic procedures performed by the department of Clinical Chemistry of the Academic Medical Center Amsterdam.

RNA isolation and real time quantitative PCR (RT-qPCR) Total RNA was extracted from snap-frozen $-80^{\circ} \mathrm{C}$ stored bladder and kidney using TriReagent (cat no. T9424, Sigma-Aldrich, Zwijndrecht, The Netherlands) followed by chloroform phase separation to obtain the aqueous RNA containing upper phase and isopropanol precipitation according to the manufacturer protocol procedure description and converted to cDNA. cDNA was synthesized using M-MLV reverse transcriptase according the procedure described in the manufacturer protocol (cat no. 28025, Thermo Scientific). Transcription was analyzed by RT-qPCR on a Roche LightCycler 480 using $2.5 \mu$ sensiFAST SYBR master mix (cat no. bio-98020, Bioline reagents, London, UK), $0.20 \mu \mathrm{l}$ forward primer, $0.20 \mu$ reverse primer (Table 1), $2.10 \mu \mathrm{l}$ distilled $\mathrm{H}_{2} \mathrm{O}$ and $1 \mu \mathrm{l} \mathrm{cDNA}$ per reaction. qPCR primers were synthesized by Eurogentec (Maastricht, The Netherlands) and described in the list below. qPCR data was analyzed based on linear regression using the LinRegPCR program, that is freely available ${ }^{18,19}$. Briefly, the LinRegPCR program imports non-baseline corrected qPCR data, performs a baseline correc-

Table 1. qPCR Primers.

\begin{tabular}{|l|l|l|l|l|}
\hline Gene & Full name & $\begin{array}{l}\text { GenBank } \\
\text { accession } \\
\text { number }\end{array}$ & Forward primer & Reverse primer \\
\hline NIx1 & NOD-like receptor X1 & $\begin{array}{l}\text { NM_001163742 } \\
\text { NM_001163743 } \\
\text { NM_178420 }\end{array}$ & TTGCCATTTGCCCAGGACCTCTT & GGATCAAGAAGGAGATATGCTCATCTGGTAG \\
\hline Tbp & $\begin{array}{l}\text { TATA box binding } \\
\text { protein }\end{array}$ & NM_013684 & GGAGAATCATGGACCAGAACA & GATGGGAATTCCAGGAGTCA \\
\hline
\end{tabular}


tion on each sample separately, determines a window-of-linearity and then uses linear regression analysis to determine the PCR efficiency per sample from the slope of the regression line. The mean PCR efficiency per amplicon and the $\mathrm{Cq}$ value per sample are used to calculate a starting concentration per sample, expressed in arbitrary fluorescence units $(\mathrm{au})^{19}$.

\section{Statistical analysis}

Data are expressed as mean \pm standard error of the mean (SEM), bacterial outgrowth data are expressed on a logarithmic scale as median scatterplot. The non-parametric Mann Whitney U test was performed for two group comparison. For all analyses, values of $P \leq 0.05$ were considered significant. All statistical analyses were performed using GraphPad Prism 5 (GraphPad Software, San Diego, CA, USA).

\section{Results}

Local NLRX1 expression in the bladder and kidney during experimental UTI

To determine whether NLRX1 expression is modulated in the murine bladder and kidney during urinary tract infection (UTI), wild-type (WT) mice were intravesically inoculated with uropathogenic E. coli and sacrificed at $24 \mathrm{~h}$ and $48 \mathrm{~h}$ after infection. Non-infected sham mice were used as controls. Real-time quantitative PCR revealed that Nlrxl transcript levels were constitutively present in the bladder and kidney (Figure 1A and B). Nlrxl transcript levels show a non-significant trend towards increased levels in the bladder after $24 \mathrm{~h}$, while levels are returned towards baseline sham levels at $48 \mathrm{~h}$ (Figure 1A). In the kidney Nlrxl transcript levels remained at baseline level $24 \mathrm{~h}$ after infection while after $48 \mathrm{~h}$ levels were significantly increased (Figure 1B). Together, these data show that in response to UTI, local Nlrxl expression is increased upon E. coli infection.
NLRX1 deficiency enhances early bacterial burden from the bladder while it does not influence bacterial burden in the kidney during experimental UTI

To investigate whether NLRX1 plays a role in bladder and kidney during lower and upper UTI, we examined bacterial loads in these organs from WT and NLRX1 knock-out (KO) mice $24 \mathrm{~h}$ and $48 \mathrm{~h}$ after inoculation with uropathogenic $E$. coli. This revealed that the bacterial outgrowth, as measured by colony forming units (CFU), in bladder tissue from NLRX1 KO mice was significantly higher at $24 \mathrm{~h}$ after infection compared to WT while at $48 \mathrm{~h}$ no differences in bacterial burden were found (Figure 2A). NLRX1 deficient mice had more improved bacterial clearance from the bladder at $48 \mathrm{~h}$ as compared to $24 \mathrm{~h}$ (Figure 2A). No differences in the amount of CFU were found between kidneys from WT and NLRX1 KO mice at both time points (Figure 2B). To monitor the local inflammatory response during infection, we next measured the levels of KC, MIP-2, MCP-1, IL-1 $\beta$, IL- 6 and TNF $\alpha$ in kidney and bladder homogenates (Figure 2C and D). The production of MIP-2 in the bladder was in NLRX1 KO mice reduced at both $24 \mathrm{~h}$ and $48 \mathrm{~h}$ after infection compared to WT animals (Figure 2C). In addition, NLRX1 KO bladders show reduced levels of MCP-1 and TNF $\alpha$ compared to WT at $48 \mathrm{~h}$, while no differences were found in $\mathrm{KC}$, IL-1 $\beta$ and IL6 levels (Figure 2C). We identified an increase in renal KC levels at $24 \mathrm{~h}$ in NLRX1 KO mice compared WT mice, whereas at $48 \mathrm{~h} \mathrm{KC}$ levels were similar between both groups (Figure 2D). At both $24 \mathrm{~h}$ and $48 \mathrm{~h}$ no differences were found in renal MIP-2, MCP-1, IL-1 $\beta$, IL-6 and TNF $\alpha$ levels between WT and NLRX1 KO mice (Figure 2D). In addition, upper UTI and NLRX1 have no significant influence on renal function as reflected by similar plasma levels of urea and creatinine between all mice (Supplementary Figure 1 A and B). Together, this indicates that the lack of NLRX1 is associated with an early
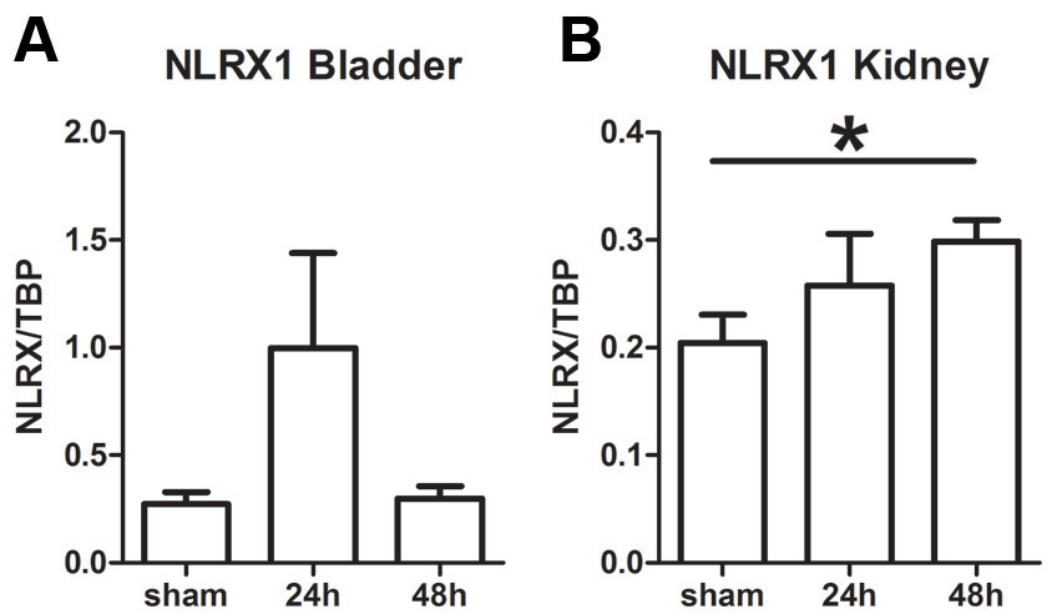

Figure 1. NLRX1 expression in bladder and kidney during experimental urinary tract infection (UTI). NIrx1 mRNA transcript levels in wild-type (WT) (A) bladder and (B) kidney from sham, and uropathogenic E. coli-inoculated mice. All data are expressed as mean \pm SEM, $n=4$ (sham) and $n=7-8$ (24h and 48h) animals per group. Statistical significance was determined by non-parametric Mann Whitney $U$ test, ${ }^{*} P<0.05$. 

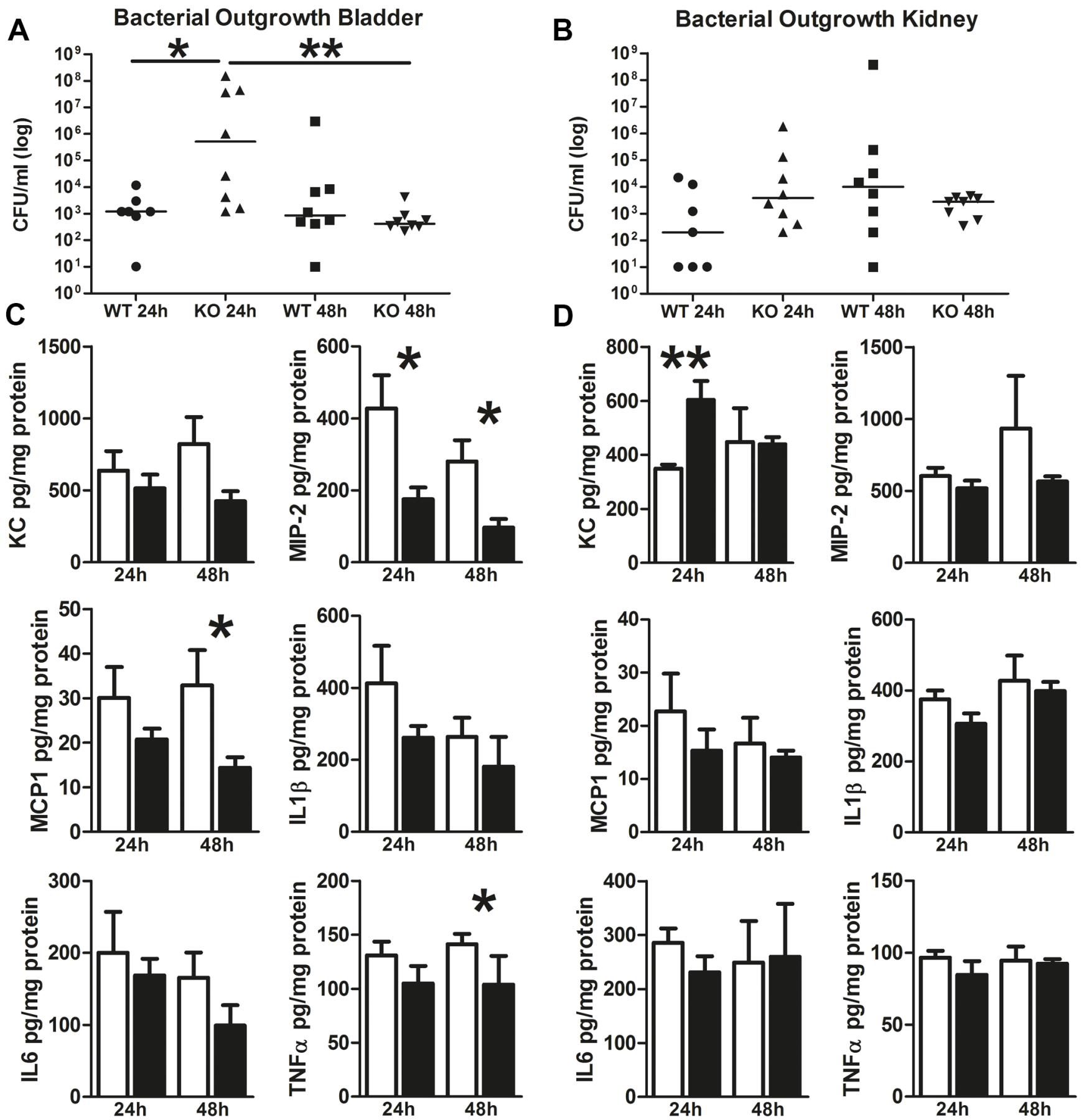

Figure 2. Bacterial outgrowth and inflammatory response in WT and NLRX1 KO bladder and kidney during experimental urinary tract infection (UTI). Outgrowth of uropathogenic E. coli expressed in colony forming units (CFU) in (A) bladder and (B) kidney homogenates from wild-type (WT) and NLRX1 knock-out (KO) mice 24h and 48h after inoculation. Levels of KC, MIP-2, MCP-1, IL-1 / IL6 and TNF $\alpha$ in (C) bladder and (D) kidney homogenates from the E. coli inoculated WT (white bars) and NLRX1 KO (black bars) mice. Data at A and B are expressed on a logarithmic scale as median scatterplot. Data at $C$ and $D$ are expressed as mean \pm SEM. For all data $n=7-8$ animals per group and statistical significance between WT and NLRX1 KO was determined by non-parametric Mann Whitney $U$ test, ${ }^{*} P<0.05$ and ${ }^{* *} P<0.01$. 
impaired ability to clear uropathogenic $E$. coli from the bladder, probably due to an impaired pro-inflammatory cytokine response, while NLRX1 deficient mice had an improved bacterial clearance from $24 \mathrm{~h}$ to $48 \mathrm{~h}$ in the bladder as compared to WT. No differences were found in bacterial burden and cytokine response in the kidney when mice were deficient for NLRX1.

NLRX1 does not affect circulating leukocyte number and local presence of activated neutrophils during experimental UTI

By analyzing inflammatory cells in the circulation we observed that the numbers of granulocytes and monocytes were equal between uninfected WT and NLRX1 KO mice (Figure 3A). A non-significant trend towards an increased presence of lymphocytes in NLRX1 KO compared to WT is shown (Figure 3A). We observed that WT and NLRX1 KO mice $24 \mathrm{~h}$ and $48 \mathrm{~h}$ after inoculation, have similar numbers of circulating leukocytes (Figure 3B). Recruitment of neutrophils in the kidney and bladder are essential for the host defense against uropathogenic E. $\operatorname{coli}^{20}$. Therefore, we determined active neutrophil presence by measuring kidney and bladder myeloperoxidase (MPO) concentrations. No differences in MPO levels were found in bladder and kidney between WT and NLRX1 KO mice at $24 \mathrm{~h}$ and $48 \mathrm{~h}$ (Figure $3 \mathrm{C}$ and $\mathrm{D}$ ), indicating a similar number of activated neutrophils.

NLRX1 is not essential for pro-inflammatory cytokine secretion in response to LPS and phagocytosis of $E$. coli by granulocytes and monocytes

Since we observed differences in bacterial outgrowth in the bladder while the number of local neutrophils after infection is equal between WT and NLRX1 KO, we investigated if NLRX1 absence causes functional changes to granulocytes and monocytes. This revealed that NLRX1 is not critical for the secretion of the pro-inflammatory cytokines $\mathrm{KC}, \mathrm{TNF} \alpha$ and IL6 after ex vivo whole blood LPS stimulation (Figure 4A, B and $\mathrm{C}$ ). To investigate if NLRX1 is important for the phagocytic activity of granulocytes and monocytes, leukocytes from WT and NLRX1 KO mice were ex vivo incubated with fluorescein labelled opsonized $E$. coli, and phagocytosis was analyzed using flow cytometry. Granulocytes and monocytes from both WT and NLRX1 KO mice show increased phagocytic activity responses when challenged with $E$. coli at $37^{\circ} \mathrm{C}$ compared to $0^{\circ} \mathrm{C}$ (Figure 4D and E). However, no differences were observed in

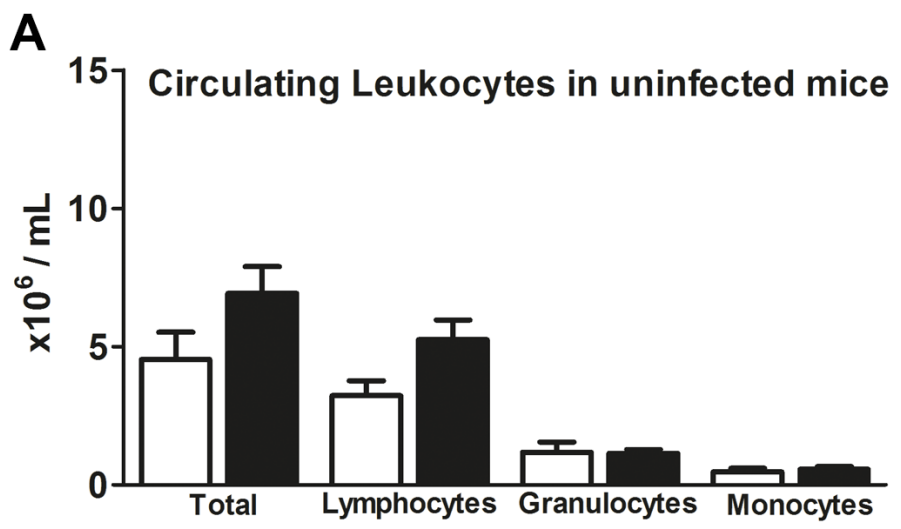

B
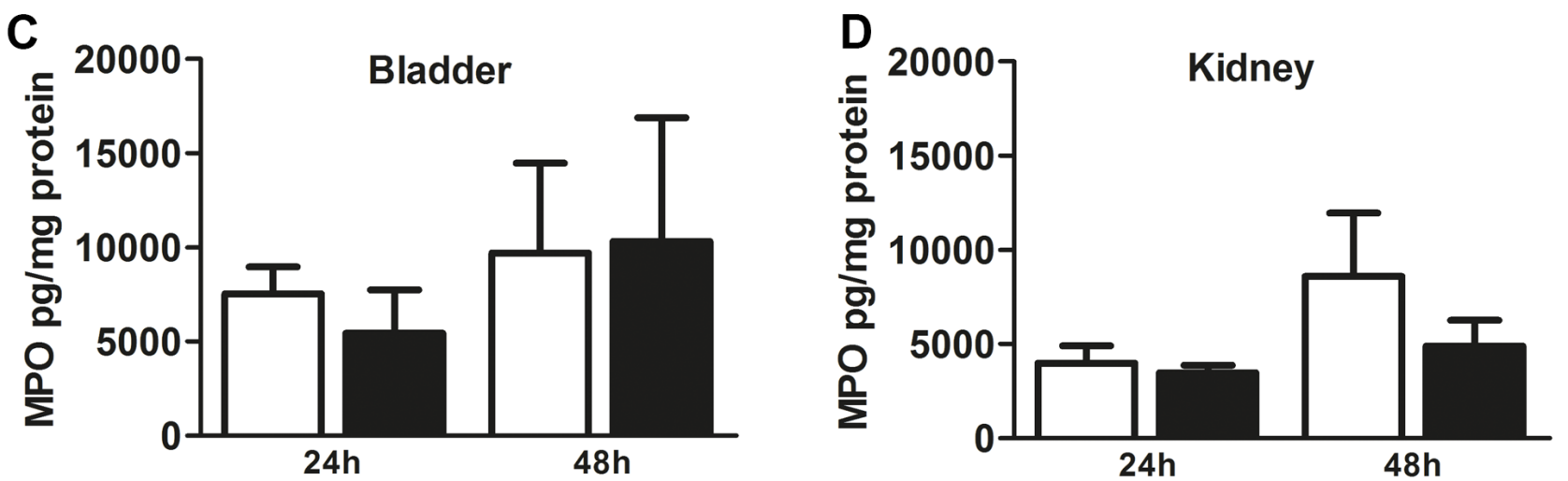

Figure 3. Circulating and local leukocyte dynamics in naïve WT and NLRX1 KO mice and upon experimental urinary tract infection (UTI). (A) Total circulating leukocyte, lymphocyte, granulocyte and monocyte cell counts in blood from uninfected wild-type (WT) (white bars) and NLRX1 knock-out (KO) (black bars) mice $n=5-6$ animals per group. (B) Circulating leukocytes in blood from WT (white bars) and NLRX1 $\mathrm{KO}$ (black bars) mice $24 \mathrm{~h}$ and $48 \mathrm{~h}$ after uropathogenic $E$. coli inoculation. MPO levels in (C) bladder and (D) kidney homogenates from $24 \mathrm{~h}$ and $48 \mathrm{~h}$ inoculated WT (white bars) and NLRX1 KO mice (black bars). All data are expressed as mean \pm SEM, $n=7-8$ (B-D) animals per group. Statistical significance between WT and NLRX1 KO was determined by non-parametric Mann Whitney $U$ test. 

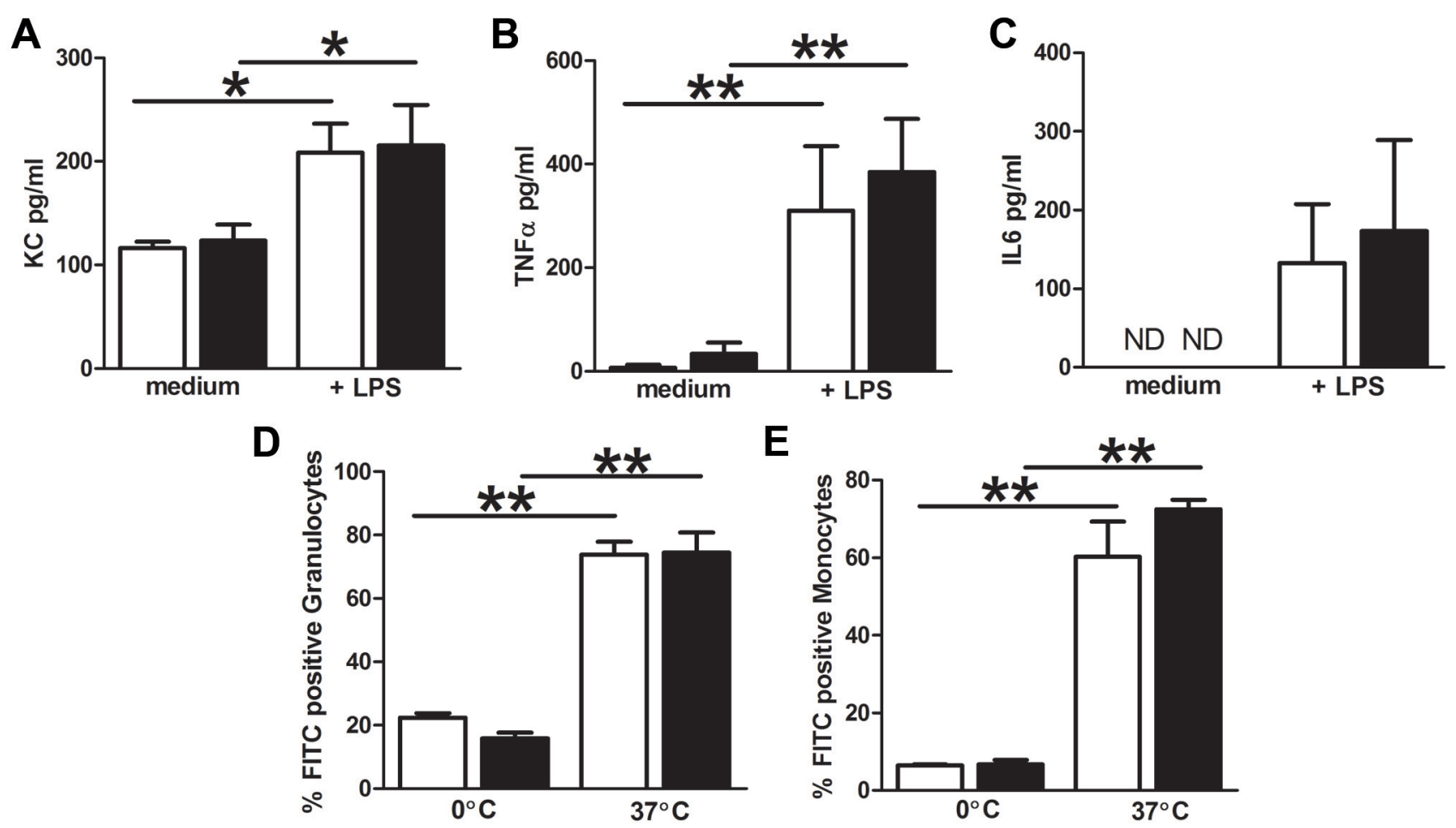

Figure 4. Cytokine secretion in response to LPS and $E$. coli phagocytosis by WT and NLRX1 KO granulocytes and monocytes. Levels of (A) KC (B) TNF $\alpha$ and (C) IL6 after 14h ex vivo LPS whole blood stimulation from wild-type (WT) (white bars) and NLRX1 knock-out (KO) (black bars). ND = not detectable. Phagocytic activity responses of (D) granulocytes and (E) monocytes from WT (white bars) and NLRX1 $\mathrm{KO}$ (black bars) mice ex vivo challenged with $E$. coli at $0^{\circ} \mathrm{C}$ and $37^{\circ} \mathrm{C}$. All data are expressed as mean $\pm \mathrm{SEM}, n=5-6$ animals per group. Statistical significance between all columns was determined by non-parametric Mann Whitney $U$ test, ${ }^{*} P<0.05$ and ${ }^{* *} P<0.01$.

the percentage of granulocytes and monocytes that undergo phagocytosis between WT and NLRX1 KO (Figure 4E and F). Together, these results suggest that the early decreased bacterial clearance in the bladders from NLRX1 KO mice cannot be explained by an impaired granulocyte or monocyte response.

Dataset 1. NLRX1 expression data - This file contains the data underlying the analysis of the NLRX1 expression in bladder and kidney as shown in Figure 1

http://dx.doi.org/10.5256/f1000research.15361.d212937

Dataset 2. In vivo mice bladder and kidney colony forming units (CFU)-, cytokine-, general marker-data and leukocyte counts in sham and after $24 \mathrm{~h}$ and $48 \mathrm{~h}$ of infection - This file contains the data underlying the analysis of the data used in Figure 2, Figure 3 and Supplementary Figure 1

http://dx.doi.org/10.5256/f1000research.15361.d212938

Dataset 3. Ex vivo FACS output data - This file contains the FACS data underlying the leukocyte composition analysis as shown in Figure 3

http://dx.doi.org/10.5256/f1000research.15361.d212939
Dataset 4. Ex vivo cytokine data - This file contains the data underlying the cytokine determination in LPS stimulated whole blood as shown in Figure 4

http://dx.doi.org/10.5256/f1000research.15361.d212940

Dataset 5. Ex vivo FACS output data on granuocyte and monocytes phagocytosis - This file contains the FACS data underlying the granuocytes and monocytes phagocytosis as shown in Figure 4

http://dx.doi.org/10.5256/f1000research.15361.d212941

\section{Discussion}

Innate immune receptors like TLRs and NLRs are known to play pivotal roles in the first line of host defense against invading pathogens. NLRX1 is an innate immune receptor that can modulate inflammatory responses $^{21}$ and cell metabolism ${ }^{9,10}$. As such NLRX1 could play a potential role during the pathophysiology of UTI. To study this we investigated the role of NLRX1 during uropathogenic E. coli-induced lower and upper UTI in mice. Although NLRX1 enhances the inflammatory cytokine response and the bacterial clearance in the bladder during early experimental UTI, we found that this receptor does 
not affect overall renal bacterial loads and inflammation during pyelonephritis. In addition, we observed that NLRX1 is not essential for pro-inflammatory cytokine secretion by granulocytes and monocytes in response to LPS nor for phagocytosis of E. coli.

In this study we investigated the role of NLRX1 in influencing bacterial burden and inflammation in bladder and kidney during experimental UTI. We found that the lack of NLRX1 is associated with an impaired ability to clear uropathogenic E. coli from the bladder at $24 \mathrm{~h}$ only, probably due to an impaired pro-inflammatory MIP-2 cytokine response which is usually needed for the recruitment of granulocytes to the site of infection $^{20,22}$ and the initiation of host defense during UTI ${ }^{23}$. Surprisingly however, the levels of bladder MPO as an indicator of neutrophil influx and the ex vivo granulocyte phagocytic capacity to ingest $E$. coli are not affected by NLRX1 while local Nlrxl expression in the bladder tended to be increased at $24 \mathrm{~h}$. Possibly, granulocyte influx is altered by NLRX1 at an earlier time point than $24 \mathrm{~h}$. Despite the impaired MIP-2, MCP-1 and $\mathrm{TNF} \alpha$ cytokine response, bacterial burden in the bladder at $48 \mathrm{~h}$, is not different in NLRX1 deficient mice compared to WT. In fact, NLRX1 KO are able to clear E. coli bacteria faster since the CFU reduction from $24 \mathrm{~h}$ to $48 \mathrm{~h}$ is significantly while bacterial levels in bladder remained the same in WT. Whereas in the kidney, the outgrowth from $24 \mathrm{~h}$ to $48 \mathrm{~h}$ in WT and NLRX1 KO remains unchanged, indicating that despite the local Nlrxl expression increase at $48 \mathrm{~h}$ NLRX1 this does not affect bacterial outgrowth in the kidney. Our study demonstrates that due to NLRX1 absence, the MIP-2 cytokine release to recruit neutrophils is less pronounced and hence possibly attenuates the early phase of the host defense against $E$. coli in the bladder without affecting later bacterial bladder burden, innate myeloid cell phagocytosis and the promotion of pyelonephritis.

NLRX1 is on the one hand described to negatively regulate NF- $\mathrm{KB}$ signaling ${ }^{12,13}$ and on the other to indirectly amplify the NF- $\kappa \mathrm{B}$ pathway ${ }^{24}$. During E. coli-induced UTI infections the $\mathrm{NF}-\kappa \mathrm{B}$ signaling pathway is via TLR4 activation one of the most important pathways for the pro-inflammatory cytokine release and the clearance of $E$. coli from the urinary tract ${ }^{25}$. We observed in NLRX1 KO bladders that despite the increased bacterial burden $24 \mathrm{~h}$ post infection, besides reduced MIP-2, the levels of pro-inflammatory cytokines TNF $\alpha$, IL6 and IL1 $\beta$ were equal in both mouse strains. Whereas at the later $48 \mathrm{~h}$ time point in the bladder and at $24 \mathrm{~h}$ and $48 \mathrm{~h}$ in the kidney, NLRX1 has no effect on pro-inflammatory cytokine response and bacterial burden. This indicates that upon early UTI, NLRX1 absence leads to a suppressed pro-inflammatory cytokine response in the bladder. Whether this is caused by an altered neutrophil influx in the early onset of infection or the ability of NLRX1 to influence NF- $\kappa \mathrm{B}$ signaling warrants further study. From our study it is however clear that NLRX1 is neither essential for whole blood pro-inflammatory KC, TNF $\alpha$ and IL6 cytokine responses to LPS, nor for bacterial phagocytosis by granulocytes and monocytes. Similar observations were done in bone marrow-derived macrophages where TNF $\alpha$ and IL6 cytokine expression remained similar in WT and NLRX1 deficient cells after a Helicobacter pylori (LPS positive) infection ${ }^{26}$. In contrast, TNF $\alpha$ and IL6 levels were increased upon NLRX1 knockdown in LPS-stimulated peritoneal macrophages ${ }^{12}$ and IL6 levels in LPS-stimulated bone marrow-derived macrophages ${ }^{13}$ indicating that NLRX1 attenuates NF- $\kappa \mathrm{B}$ signaling. In contrast, increased NF- $\kappa \mathrm{B}$ signaling upon LPS positive Shigella flexineri infection was observed in NLRX1 overexpressing epithelial cells ${ }^{24}$. Possibly, the role of NLRX1 varies between cell types involved in host defense, such as myeloid cells and parenchymal cells, during different time points of infection and different ligands. Together, we observed that NLRX1 does not affect the pro-inflammatory cytokine response after LPS challenge in granulocytes and monocytes, whereas previous studies show that in macrophages and epithelial cells NLRX1 can behave differently ${ }^{12,13,24}$. Indeed, during UTI epithelial cells are important in activating inflammation via various signaling pathways ${ }^{25}$. Based on our results that granulocyte and macrophage functioning are not affected by NLRX1, we assume that during UTI NLRX1 plays a role in the early bacterial burden in the bladder by activating the pro-inflammatory cytokine response in parenchymal cells via NF- $\mathrm{KB}$.

Besides its role in immune regulation, we previously observed that NLRX1 functioning extends to the control of mitochondrial activity, oxidative stress and cellular metabolism in parenchymal cells of the kidney and liver, ${ }^{9}$. Macrophages and in particular neutrophils contribute during infections to the host defense via oxidative burst $\mathrm{t}^{27,28}$. From our data it is not clear if NLRX1 plays a role in the oxidative burst in myeloid cells during UTI. However, a previous study showed that NLRX1 plays no significant role in ROS production of LPS activated neutrophils and macrophages ${ }^{13}$. Together, our data indicates that there is a role for NLRX1 during UTI in the bladder by activating the pro-inflammatory cytokine response, while no direct role for NLRX1 is observed in myeloid cells.

\section{Conclusion}

We report that NLRX1 is important in attenuating the early bacterial burden in the bladder by enhancing the local proinflammatory cytokine response but has no effect on the development of pyelonephritis.

\section{Data availability}

Dataset 1: NLRX1 expression data - This file contains the data underlying the analysis of the NLRX1 expression in bladder and kidney as shown in Figure 1. 10.5256/f1000research.15361. d21293729

Dataset 2: In vivo mice bladder and kidney colony forming units (CFU)-, cytokine-, general marker-data and leukocyte counts in sham and after $24 \mathrm{~h}$ and $48 \mathrm{~h}$ of infection - This file contains the data underlying the analysis of the data used in Figure 2, Figure 3 and Supplementary Figure 1. 10.5256/f1000research.15361. d212938

Dataset 3: Ex vivo FACS output data - This file contains the FACS data underlying the leukocyte composition analysis as shown in Figure 3. 10.5256/f1000research.15361.d21293931 
Dataset 4: Ex vivo cytokine data - This file contains the data underlying the cytokine determination in LPS stimulated whole blood as shown in Figure 4. 10.5256/f1000research.15361. d2 $12940^{32}$

Dataset 5: Ex vivo FACS output data on granuocyte and monocytes phagocytosis - This file contains the FACS data underlying the granuocytes and monocytes phagocytosis as shown in Figure 4. 10.5256/f1000research.15361.d212941 33
Competing interests

No competing interests were disclosed.

Grant information

This study was supported by The Netherlands Organization for Scientific Research NWO grant [91712386] to JCL.

The funders had no role in study design, data collection and analysis, decision to publish, or preparation of the manuscript.

\section{Supplementary material \\ Supplementary Figure 1. Renal function of wild-type (WT) and NLRX1 knock-out (KO) mice during experimental urinary tract infections (UTI)}

Plasma levels of renal function markers (A) urea and (B) creatinine from sham, 24h and 48h uropathogenic Escherichia coli inoculated WT (white bars) and NLRX1 KO (black bars) mice. All data are expressed as mean \pm SEM, $n=3-4$ (sham) and $n=7-8$ (24h and 48h) animals per group. Statistical significance was determined by non-parametric Mann Whitney $U$ test.

Click here to access the data.

1. Kawai T, Akira S: The roles of TLRs, RLRs and NLRs in pathogen recognition. Int Immunol. 2009; 21(4): 317-337.

PubMed Abstract | Publisher Full Text | Free Full Text

2. Creagh EM, O'Neill LA: TLRs, NLRs and RLRs: a trinity of pathogen sensors that co-operate in innate immunity. Trends Immunol. 2006; 27(8): 352-357. PubMed Abstract | Publisher Full Text

3. Foxman B: The epidemiology of urinary tract infection. Nat Rev Urol. 2010; 7(12): 653-660.

PubMed Abstract | Publisher Full Text

4. Pellé G, Vimont S, Levy PP, et al:: Acute pyelonephritis represents a risk factor impairing long-term kidney graft function. Am J Transplant. 2007; 7(4): 899-907. PubMed Abstract | Publisher Full Text

5. Ragnarsdottir B, Lutay N, Grönberg-Hernandez J, et al:: Genetics of innate immunity and UTI susceptibility. Nat Rev Urol. 2011; 8(8): 449-468. PubMed Abstract | Publisher Full Text

6. Shepherd AK, Pottinger PS: Management of Urinary Tract Infections in the Era of Increasing Antimicrobial Resistance. Med Clin North Am. 2013; 97(4): $737-757$, xii.

PubMed Abstract | Publisher Full Text

7. Sanchez GV, Master RN, Karlowsky JA, et al.: In vitro antimicrobial resistance of urinary Escherichia coli isolates among U.S. outpatients from 2000 to 2010. Antimicrob Agents Chemother. 2012; 56(4): 2181-2183. PubMed Abstract | Publisher Full Text | Free Full Tex

8. Leemans JC, Kors L, Anders HJ, et al.: Pattern recognition receptors and the inflammasome in kidney disease. Nat Rev Nephrol. 2014; 10(7): 398-414. PubMed Abstract | Publisher Full Text

9. Kors L, Rampanelli E, Stokman G, et al.: Deletion of NLRX1 increases fatty acid metabolism and prevents diet-induced hepatic steatosis and metabolic syndrome. Biochim Biophys Acta. 2018; 1864(5 Pt A): 1883-1895. PubMed Abstract | Publisher Full Text

10. Stokman G, Kors L, Bakker PJ, et al:: NLRX1 dampens oxidative stress and apoptosis in tissue injury via control of mitochondrial activity. $J$ Exp Med. 2017; 214(8): 2405-2420 PubMed Abstract | Publisher Full Text | Free Full Text

11. Moore CB, Bergstralh DT, Duncan JA, et al:: NLRX1 is a regulator of mitochondrial antiviral immunity. Nature. 2008; 451(7178): 573-577. PubMed Abstract | Publisher Full Text

12. Xia X, Cui J, Wang HY, et al.: NLRX1 negatively regulates TLR-induced NF-кB signaling by targeting TRAF6 and IKK. Immunity. 2011; 34(6): 843-53. PubMed Abstract | Publisher Full Text | Free Full Text

13. Allen IC, Moore CB, Schneider M, et al: NLRX1 protein attenuates inflammatory responses to infection by interfering with the RIG-I-MAVS and TRAF6-NF-KB signaling pathways. Immunity. 2011; 34(6): 854-865. PubMed Abstract | Publisher Full Text | Free Full Text

14. Soares F, Tattoli I, Wortzman ME, et al:: NLRX1 does not inhibit MAVSdependent antiviral signalling. Innate Immun. 2013; 19(4): 438-48. PubMed Abstract | Publisher Full Text

15. Leemans JC, Butter LM, Teske GJ, et al:: The toll interleukin-1 receptor (IL-1R) $8 /$ single Ig domain IL-1R-related molecule modulates the renal response to bacterial infection. Infect Immun. 2012; 80(11): 3812-3820. PubMed Abstract | Publisher Full Text | Free Full Text

16. Roelofs JJ, Teske GJ, Bonta PI, et al.: Plasminogen activator inhibitor-1 regulates neutrophil influx during acute pyelonephritis. Kidney Int. 2009; 75(1): $52-59$.

PubMed Abstract | Publisher Full Text

17. Lattenist L, Teske G, Claessen N, et al:: The lectin like domain of thrombomodulin is involved in the defence against pyelonephritis. Thromb Res. 2015; 136(6): 1325-1331.

PubMed Abstract | Publisher Full Text

18. Ramakers C, Ruijter JM, Deprez RH, et al:: Assumption-free analysis of quantitative real-time polymerase chain reaction (PCR) data. Neurosci Lett. 2003; 339(1): 62-66.

PubMed Abstract | Publisher Full Text

19. Ruijter JM, Ramakers C, Hoogaars WM, et al.: Amplification efficiency: linking baseline and bias in the analysis of quantitative PCR data. Nucleic Acids Res. 2009; 37(6): e45.

PubMed Abstract | Publisher Full Text | Free Full Text

20. Haraoka M, Hang L, Frendéus B, et al:: Neutrophil recruitment and resistance to urinary tract infection. $J$ Infect Dis. 1999; 180(4): 1220-1229. PubMed Abstract | Publisher Full Text

21. Xiao TS, Ting JP: NLRX1 has a tail to tell. Immunity. 2012; 36(3): 311-312. PubMed Abstract | Publisher Full Text | Free Full Text

22. Adams DH, Lloyd AR: Chemokines: leucocyte recruitment and activation cytokines. Lancet. 1997; 349(9050): 490-495.

PubMed Abstract | Publisher Full Text

23. Olszyna DP, Florquin S, Sewnath M, et al:: CXC chemokine receptor 2 
contributes to host defense in murine urinary tract infection. $J$ Infect Dis. 184(3): 301-307

PubMed Abstract | Publisher Full Text

24. Tattoli I, Carneiro LA, Jéhanno M, et al.: NLRX1 is a mitochondrial NOD-like receptor that amplifies NF-kappaB and JNK pathways by inducing reactive oxygen species production. EMBO Rep. 2008; 9(3): 293-300.

PubMed Abstract | Publisher Full Text | Free Full Text

25. Chassin C, Goujon JM, Darche S, et al:: Renal collecting duct epithelial cells react to pyelonephritis-associated Escherichia coli by activating distinct TLR4dependent and -independent inflammatory pathways. J Immunol. 2006; 177(7) 4773-4784.

PubMed Abstract | Publisher Full Text

26. Philipson CW, Bassaganya-Riera J, Viladomiu M, et al.: Modeling the Regulatory Mechanisms by Which NLRX1 Modulates Innate Immune Responses to Helicobacter pylori Infection. PLoS One. 2015; 10(9): e0137839. PubMed Abstract | Publisher Full Text | Free Full Text

27. Ricevuti G: Host tissue damage by phagocytes. Ann N Y Acad Sci. 1997; 832(1) $426-48$

PubMed Abstract | Publisher Full Text

28. Quinn MT, Gauss KA: Structure and regulation of the neutrophil respiratory burst oxidase: comparison with nonphagocyte oxidases. J Leukoc Biol. 2004;
76(4): 760-781.

PubMed Abstract | Publisher Full Text

29. Kors L, Butter LM, Claessen N et al: Dataset 1 in: NLRX1 is not involved in the host defense against Escherichia coli induced pyelonephritis. F1000Research. 2018.

http://www.doi.org/10.5256/f1000research.15361.d212937

30. Kors L, Butter LM, Claessen N, et al:: Dataset 2 in: NLRX1 is not involved in the host defense against Escherichia coli induced pyelonephritis. F1000Research. 2018.

http://www.doi.org/10.5256/f1000research.15361.d212938

31. Kors L, Butter LM, Claessen N, et al:: Dataset 3 in: NLRX1 is not involved in the host defense against Escherichia coli induced pyelonephritis. F1000Research. 2018.

http://www.doi.org/10.5256/f1000research.15361.d212939

32. Kors L, Butter LM, Claessen N, et al:: Dataset 4 in: NLRX1 is not involved in the host defense against Escherichia coli induced pyelonephritis. F1000Research. 2018.

http://www.doi.org/10.5256/f1000research.15361.d212940

33. Kors L, Butter LM, Claessen N, et al:: Dataset 5 in: NLRX1 is not involved in the host defense against Escherichia coli induced pyelonephritis. F1000Research. 2018.

http://www.doi.org/10.5256/f1000research.15361.d212941 


\section{Open Peer Review}

\section{Current Peer Review Status:}

\section{Version 1}

Reviewer Report 15 January 2019

https://doi.org/10.5256/f1000research.16740.r42570

(C) 2019 Justice S. This is an open access peer review report distributed under the terms of the Creative Commons Attribution License, which permits unrestricted use, distribution, and reproduction in any medium, provided the original work is properly cited.

\section{Sheryl Justice}

The Research Institute at Nationwide Children's Hospital, Columbus, OH, USA

The manuscript by Kors et al. explores the role of the nod-like receptor X1 (NLRX1) during urinary tract infection (UTI). Given the intracellular populations during UTI, the potential role of intracellular immune regulators could be important and the investigations are understudied, making the work significant. Better understanding of the immune modulators could lead to new approaches to treat UTI. The investigators use a knock out mouse to evaluate the bacterial burden in the urinary tissues as well as the immune responses. In addition, the investigators evaluate the efficacy of phagocytosis of E. coli by granulocytes and macrophages. There are alternative conclusions that are more consistent with the published literature and better explain the data than the those provided by the investigators. The analysis of the circulating immune cells was important to exclude potential confounding differences in overall immune capacity.

Major concerns:

1. The use of 10 e8 as the inoculum is known to induce early exfoliation of the superficial bladder epithelial cells in C57BI/6 mice (at about 16 hours), and most groups use a lower inoculum to evaluate the acute phase of UTI. The bacterial burden observed in the wild type at 24 hours is consistent with prior studies that the early exfoliation leads to establishment of a quiescent intracellular reservoir between $10 \mathrm{e} 3$ and $10 \mathrm{e} 4$. The similarity of this burden at 48 hours further supports this conclusion. In this scenario, the conclusion for the NLRX1 studies would be that the exfoliation is delayed. This would be a very interesting observation given that our understanding of the host responses that modulate exfoliation in response to infection is incomplete. Microscopic studies need to be performed to evaluate the exfoliation status to draw conclusions. Please provide the limit of detection on the graphs for the bacterial burden.

2. The immune response is known to induce morphological changes in UPEC that will reduce the CFU recovered. The loss of NLDX1 could alter these changes and an apparent increase in CFU could be observed, but the bacterial biomass could be similar. Given the bacterial burden of the parent, the conclusion proposed in point 1 is favored. Microscopic analysis would distinguish between these conclusions. 
3. In the discussion, the statement that begins "In fact, NLRX1 KO mice are able to clear E. coli faster...." Is not consistent with what is known about the infection. Earlier time points (6 or 16 hours) would certainly reveal that there is a higher burden of UPEC in the WT and as such, the opposite conclusion would be made. It is highly unlikely that the burden in the WT mice would start at 10 e 3 and remain there throughout the course of infection. Even if this were the case, the above conclusion would still not be supported since the burden is lower in WT mice at 24 hours. Inclusion of an earlier time point is needed.

4. Although statistically significant, IL- 6 changes are modest and are observed at the later stages of the acute infection. There are multiple studies that have quantified IL- 6 and correlated the effect of changes in IL- 6 on the infection outcome. The results should be presented in context with the published literature.

5. Investigation for the potential role in myeloid cell function is intriguing. However, as the investigators indicated, there are potentially other functions that may be affected. The ability of the phagocytes to kill UPEC would be an interesting test and would provide mechanistic insight into the role of NLDX1 in this system.

6. Please provide power calculations for the immune studies, why were fewer mice included in this portion of the study? Was the burden determined for these mice?

7. The dataset for the FACs analyses were not included (the cytokine data was uploaded twice). Please provide an example of the gating strategy

Minor concerns:

1. In the methods for the animal experiments "human" should be "humane".

Is the work clearly and accurately presented and does it cite the current literature? Partly

Is the study design appropriate and is the work technically sound? Partly

Are sufficient details of methods and analysis provided to allow replication by others? Yes

If applicable, is the statistical analysis and its interpretation appropriate? Yes

Are all the source data underlying the results available to ensure full reproducibility? No

Are the conclusions drawn adequately supported by the results?

No

Competing Interests: No competing interests were disclosed. 
Reviewer Expertise: urinary tract infection, Escherichia coli, bacterial pathogenesis

I confirm that I have read this submission and believe that I have an appropriate level of expertise to confirm that it is of an acceptable scientific standard, however I have significant reservations, as outlined above.

Author Response 03 Apr 2019

Lotte Kors, UMC Amsterdam Location AMC, Amsterdam, The Netherlands

Dear Dr. Justice,

Thank you for the thoughtful comments. We have addressed the comments and questions raised and have detailed our response below.

1. The use of 10 e8 as the inoculum is known to induce early exfoliation of the superficial bladder epithelial cells in C57BI/6 mice (at about 16 hours), and most groups use a lower inoculum to evaluate the acute phase of UTI. The bacterial burden observed in the wild type at 24 hours is consistent with prior studies that the early exfoliation leads to establishment of a quiescent intracellular reservoir between $10 \mathrm{e} 3$ and $10 \mathrm{e} 4$. The similarity of this burden at 48 hours further supports this conclusion. In this scenario, the conclusion for the NLRX1 studies would be that the exfoliation is delayed. This would be a very interesting observation given that our understanding of the host responses that modulate exfoliation in response to infection is incomplete. Microscopic studies need to be performed to evaluate the exfoliation status to draw conclusions. Please provide the limit of detection on the graphs for the bacterial burden.

Reply:

We appreciate the reviewer's alternative interpretation of the data and payed attention to this possibility in the second paragraph of the discussion as follows: "It is in addition possible that processes like delayed $E$. coli-attachment, invasion and modulated exfoliation or factor secretion of superficial bladder cells contribute to the increased presence of $E$. coli bacteria in NLRX1 KO bladders at 24h. Whether or not direct or indirect NLRX1-mediated modulation of bladder cells contribute to the bacterial burden has not been proven yet and warrants further study.". We agree that microscopic studies of the superficial bladder epithelial cells to evaluate exfoliation would be interesting to add however unfortunately we used all bladder material for the study of CFU counts. Instead we added this possibility as stated above. We finally would like to stress that $24 \mathrm{~h}$ after exfoliation effective regeneration is induced making it probably difficult to convincingly show exfoliation at $48 \mathrm{~h}$ (1). We provided the detection limit to the figure legends.

1. Niall F. Davis and Hugh D. Flood. The Pathogenesis of Urinary Tract Infections. In: Clinical Management of Complicated Urinary Tract Infection. 2011

2. The immune response is known to induce morphological changes in UPEC that will reduce the CFU recovered. The loss of NLDX1 could alter these changes and an apparent increase in CFU could be observed, but the bacterial biomass could be similar. Given the bacterial burden of the parent, the conclusion proposed in point 1 
is favored. Microscopic analysis would distinguish between these conclusions.

Reply:

The assumption that the changes by NLRX1 loss will change the immune response and as such the UPEC is able to indirectly cause an increase in CFU without affecting bacterial biomass is interesting. We however showed in our paper by the ex vivo experiments in granulocytes and monocytes and by the various cytokine and chemokine levels in the bladder that when the bacterial outgrowth is increased, the immune response is not changed in absence of NLRX1. In addition, CFU counts and not bacterial biomass is as far we know the standard to measure bacterial burden in the used UTI model. This together with our main conclusion that NLRX1 is not involved in the host defense against $E$. coli-induced pyelonephritis we believe that further research on morphological changes to the UPEC is beyond the scope of the article.

3. In the discussion, the statement that begins "In fact, NLRX1 KO mice are able to clear E. coli faster...." Is not consistent with what is known about the infection. Earlier time points (6 or 16 hours) would certainly reveal that there is a higher burden of UPEC in the WT and as such, the opposite conclusion would be made. It is highly unlikely that the burden in the WT mice would start at 10 e3 and remain there throughout the course of infection. Even if this were the case, the above conclusion would still not be supported since the burden is lower in WT mice at 24 hours. Inclusion of an earlier time point is needed.

Reply:

This is an excellent point raised by the reviewer. We agree with the reviewer that based on other studies the bladder bacterial burden in the WT is likely increased at an earlier time point than $24 \mathrm{~h}$ and as such the results will be interpreted differently than described in the original discussion. Therefore we revised this part of the discussion as follows: "We found that the lack of NLRX1 is associated with an increased bacterial bladder burden at $24 \mathrm{~h}$. Previous studies by us (unpublished data) and others (2) show that the peak in uropathogenic $E$. coli outgrowth from C57BL6 mice bladders is observed before $24 \mathrm{~h}$. This, together with our observations, indicates that the bacterial clearance in the NLRX1 deficient bladder is delayed compared to WT". Inclusion of earlier time points will give insights in the kinetics of UPEC burden in the WT bladder, which has as indicated already been done previously. However, adding an earlier time point retrospectively in the current study to analyze CFU kinetics is not valid since there are always intra-experimental variations in the alive inoculum size that can only be verified in retrospect (a day after the inoculum is given to the animals). This would imply that we have to repeat all the in vivo experiments which is for ethical reasons not acceptable by our institute.

2. Mulvey MA, Schilling JD, Hultgren SJ. Establishment of a persistent Escherichia coli reservoir during the acute phase of a bladder infection. Infect. Immun.

2001;69(7):4572-4579.

4. Although statistically significant, IL- 6 changes are modest and are observed at the 
later stages of the acute infection. There are multiple studies that have quantified IL6 and correlated the effect of changes in IL- 6 on the infection outcome. The results should be presented in context with the published literature.

Reply:

As can be seen from figure $2 C$ and $D$ and figure $4 C$ there is no statistical significant difference in IL- 6 between WT and NLRX1 deficient kidney, bladder and whole blood. We however agree that putting our results in the context with the published literature will benefit the discussion and did this in the third discussion paragraph.

5. Investigation for the potential role in myeloid cell function is intriguing. However, as the investigators indicated, there are potentially other functions that may be affected. The ability of the phagocytes to kill UPEC would be an interesting test and would provide mechanistic insight into the role of NLDX1 in this system.

Reply:

We agree with the reviewer that investigating the oxidative burst of myeloid cells in response to UPEC would be interesting. However as our main message is that NLRX1 is not involved in the host defense against E. coli induced pyelonephritis we believe that adding such an experiment is beyond the scope of this paper. As an alternative we mention in the discussion that from our data it is not clear if NLRX1 plays a role in the oxidative burst in myeloid cells during UTI.

6. Please provide power calculations for the immune studies, why were fewer mice included in this portion of the study? Was the burden determined for these mice?

Reply:

Based on the protocol optimized in our institute we observed that ex vivo experiments have a lower variation-coefficient than in vivo experiments and for ethical reasons we therefore included less mice. In order to increase clarity on this point we now describe the calculation in the material and method section: "To be able to reach a statistical significant effect of NLRX1 deficiency the number of 6 mice per experimental group was assessed with an unpaired t-test based on a variation coefficient of $10 \%$, a minimal relative effect of $30 \%$, a significance of $5 \%$ and a power of $80 \%$."

7. The dataset for the FACs analyses were not included (the cytokine data was uploaded twice). Please provide an example of the gating strategy

Reply:

Unfortunately the FACS and Cytokine data were mixed up and we changed this. We provided the FACS gating strategy in Supplemental figure 2.

Minor concerns:

In the methods for the animal experiments "human" should be "humane"

Reply:

We changed this. 
Competing Interests: No competing interests were disclosed.

Reviewer Report 30 August 2018

https://doi.org/10.5256/f1000research.16740.r36871

(C) 2018 Knapp S. This is an open access peer review report distributed under the terms of the Creative Commons Attribution License, which permits unrestricted use, distribution, and reproduction in any medium, provided the original work is properly cited.

\section{Sylvia Knapp}

Department of Medicine I, Medical University of Vienna, Vienna, Austria

This report documents predominantly negative data by showing that NLRX1 does not seem to substantially alter the innate immune response during murine urinary tract infection. NLRX1 is a member of the Nod-like receptor family, which plays a role in mitochondrial activity and has mainly been implicated in negative regulation of anti-viral and TLR-triggered inflammation.

The report is well written, all data are explained in sufficient detail and presented well. By comparing wild type and NIrx1-deficient mice that were infected with an uropathogenic strain of E.coli, the authors detected transient differences in the inflammatory response (chemokine) and bacterial clearance (bladder, early timepoint), without any consequence on later bacterial elimination (i.e. 48h) and progression towards pyelonephritis. Likewise, using whole blood assays (cytokine secretion and phagocytosis), NLRX1 did not confer any alterations in the inflammatory or phagocytic response to LPS or whole bacteria.

The "conclusion sentence" of the article sounds somewhat stronger than the conclusions drawn and discussed in the entire manuscript (including the title): stating that "NLRX1 is important in attenuating the early bacterial burden in the bladder by enhancing the local pro-inflammatory cytokine response" exaggerates the fact that only MIP2 levels were reduced in NIrx1deficient bladders (without any consequence on MPO levels). I suggest rewording this sentence.

Comment to source data: Dataset 3 and 4 are mixed up (therefore I checked "partly").

It seems that these experiments were only performed once, i.e. no replicate experiments. I suggest stating this in the methods, possibly also providing an explanation for this.

Is the work clearly and accurately presented and does it cite the current literature? Yes

Is the study design appropriate and is the work technically sound? Yes

Are sufficient details of methods and analysis provided to allow replication by others? 
Yes

If applicable, is the statistical analysis and its interpretation appropriate?

Yes

Are all the source data underlying the results available to ensure full reproducibility? Partly

Are the conclusions drawn adequately supported by the results?

Yes

Competing Interests: No competing interests were disclosed.

I confirm that I have read this submission and believe that I have an appropriate level of expertise to confirm that it is of an acceptable scientific standard.

\section{Author Response 03 Apr 2019}

Lotte Kors, Amsterdam UMC location AMC, Amsterdam, The Netherlands

Dear Dr. Knapp,

Thank you for the thoughtful comments. We have addressed the comments and questions raised and have detailed our response below.

The "conclusion sentence" of the article sounds somewhat stronger than the conclusions drawn and discussed in the entire manuscript (including the title): stating that "NLRX1 is important in attenuating the early bacterial burden in the bladder by enhancing the local pro-inflammatory cytokine response" exaggerates the fact that only MIP2 levels were reduced in N/rx1deficient bladders (without any consequence on MPO levels). I suggest rewording this sentence.

Reply:

We agree with the reviewer that the conclusion sentence is somewhat strong compared to the overall message of the article and we therefore reworded this sentence. The conclusion in the first version was based in addition to MIP2 levels on the observation (as discussed in the third paragraph of the discussion) that at $24 \mathrm{~h}$ the bacterial burden is increased in the NLRX1 KO bladders while the pro-inflammatory cytokine levels remain at WT level.

Comment to source data: Dataset 3 and 4 are mixed up (therefore I checked "partly").

Reply:

We changed the titles of the datasets.

It seems that these experiments were only performed once, i.e. no replicate experiments. I suggest stating this in the methods, possibly also providing an explanation for this.

Reply:

The experiments were performed in vivo and ex vivo, the data shown is based on biological replicates and one animal is indicated in the figures by $n$. For ethical reasons these experiments were performed once. 
Competing Interests: No competing interests were disclosed.

The benefits of publishing with F1000Research:

- Your article is published within days, with no editorial bias

- You can publish traditional articles, null/negative results, case reports, data notes and more

- The peer review process is transparent and collaborative

- Your article is indexed in PubMed after passing peer review

- Dedicated customer support at every stage

For pre-submission enquiries, contact research@f1000.com 